https://helda.helsinki.fi

Writing in the context of unstable norms : teaching portfolios as a genre of academic recruitment

Solin, Anna Maria Aulikki

2018-11

Solin , A M A 2018 , ' Writing in the context of unstable norms : teaching portfolios as a genre of academic recruitment ' , International Journal of Applied Linguistics, vol. 28 , no. 3 , pp. 424-437 . https://doi.org/10.1111/ijal.12213

http://hdl.handle.net/10138/326546

https://doi.org/10.1111/ijal.12213

unspecified

acceptedVersion

Downloaded from Helda, University of Helsinki institutional repository.

This is an electronic reprint of the original article.

This reprint may differ from the original in pagination and typographic detail.

Please cite the original version. 


\section{Writing in the context of unstable norms: teaching portfolios as a genre of academic recruitment}

\section{Introduction}

In the lives of both organisations and individuals, new genres are taken into use and old ones are discarded or transformed. Sometimes new genres slip into existing genre repertoires easily and without fuss. In this article, the focus is on a genre whose take-up has been all but straightforward.

The context studied is academia, a sphere which has experienced major changes in recent years, including changes which have affected linguistic practices. This setting is marked by well-established genre repertoires and strong writing traditions, but it has also adopted and created many new genres as a result of, for example, new practices of administration and management (see e.g. Connell and Galasiński (1998) on academic mission statements and Hyon (2011) on tenure and promotion letters). The article presents a case study of a genre used in academic recruitment: the teaching portfolio. This genre was first introduced in the 1990s and has since spread to academic institutions around the globe. There is some consensus on what the genre can be used for - for example the qualitative evaluation of applicants' teaching record. However, as will be shown below, there remains a great deal of variation in how different writers and readers understand it.

The teaching portfolio model originates in North America (see e.g. CAUT, 1986; Seldin, 1993). The present study explores how this globally available model was taken up in Finnish academic communities. The genre was introduced into Finnish universities to complement or replace the $\mathrm{CV}$ as a type of document where applicants describe their qualifications for the post they are seeking. Thus, the analysis also illustrates how genre resources travel between different contexts and the varied take-ups which may result (see Blommaert, 2010).

The teaching portfolio has been a contested genre in Finnish academia ever since it was first introduced. Portfolios have been subject to debate in the corridors of university departments, in portfolio writing courses and in staff magazines. The debates have particularly concerned those content elements which depart from the traditional CV model: while a CV can take the form of a factual list of qualifications, the normative teaching portfolio should contain both 
evaluative and reflective elements. The analysis focuses on how writers orient to producing this high-stakes genre in a context where genre norms are contested and unstable.

The portfolio genre is analysed from the perspective of norm conflicts: the adoption of the genre triggered negotiations over genre norms among members of different disciplinary communities, between researchers and administrators, between portfolio enthusiasts and critics. The analysis makes use of two concepts recently discussed in discourse studies: the polycentricity of norms and indexical orders (see below).

There are few published studies so far which look at teaching portfolios from a genre perspective. Most studies discuss teaching portfolios from the point of view of teaching quality evaluation (e.g. Knapper \& Wright, 2001), portfolio implementation in higher education institutions (e.g. Leggett \& Bunker, 2006; Wouters et al., 2014) or the use of the genre in teacher education (e.g. Pires Pereira, 2014). Moreover, many papers are prescriptive rather than descriptive in orientation. A good example is Coppola (2002), which gives advice on how to write "Statements on Philosophy", a key element of the US portfolio model.

The analysis focuses on applicants who produced a teaching portfolio in the context of applying for a teaching post at a large Finnish university. The main data consists of teaching portfolio texts and text-based interviews with the applicants. The analysis also draws on interviews with administrative staff and document data, such as local portfolio guidelines. The research questions are:

- What kinds of normative orders do the interviewees describe as being relevant to the writing of a teaching portfolio?

- What kinds of norm conflicts do the interviewees point to?

- What linguistic and textual choices do applicants make in their teaching portfolios, related to the norm conflicts raised in the interviews?

In the following section, the study is positioned within existing frameworks of genre research. It also explains in more detail the relevance of the concepts order of indexicality and polycentricity to the analysis. 


\section{Genre and normative orders}

Teaching portfolios are analysed from the perspective of genre research and, more specifically, approaches which analyse genres as social action (Miller, 1984) and as dynamic resources (Bakhtin, 1986). Of the different schools of genre research, the analysis draws primarily on rhetorical genre studies (e.g. Devitt, 2004; see Solin, 2009 for a review). The influential body of work by Swales on academic genres (e.g. 1990, 2004) has also shaped the research design. In line with these traditions, genres are here defined as relatively stable types of linguistic action available in and recognised by a community of users. Genre norms are understood as context-specific, variable and subject to negotiation.

Norms of language use are conceptualised as socially based and responsive to situational constraints (Piippo, 2012). Rather than analysing how genre texts relate to a stable, predetermined set of norms, the study focuses on the situated and variable nature of norms. Such a conceptualisation encourages the analyst to ask how shared beliefs about acceptable linguistic behaviour are created and how they are adapted and mediated to others.

The adoption of a new genre typically requires guidelines regarding genre form as well as a shared understanding of what the genre will be used for and why it is needed. In institutional settings, genre form is often explicitly regulated: norms regarding structure and content are centrally created and disseminated via a written code. However, such "centre norms" are also negotiated and reworked in different situations of use. As shown in earlier research (e.g. Beaufort, 2000; Reiff \& Bawarshi, 2011), learning to write new genres is not simply a process of internalising official guidelines or other advice on genre form. Instead, we should understand norms as coming to life locally, in specific settings, and potentially as influenced by different normative orders. Blommaert (2005, p. 75) emphasises that language users typically operate in polycentric environments: language users are able and obliged to orient to different sets of potentially relevant norms.

Discourse analysts and sociolinguists have in recent years proposed various ways of conceptualising normativity. A key assumption in the analysis of norm conflicts is that different "normative orders" are at work in communities. That is, norms governing language use are systematically ordered to some degree. In the analysis of norm conflicts, I have found Blommaert's interpretation of the concept of "order of indexicality" (originating in Silverstein's work) particularly useful (see Blommaert, 2005, 2010; Silverstein, 2003). The 
term "indexicality" points to that the meaning of linguistic expressions is context-dependent; features of language use may gain different social meanings depending on the context of use.

Drawing on Silverstein, Blommaert suggests that indexical meanings come to be ordered into relatively systematic “indexical orders". In other words, particular linguistic features (for example, non-normative pronunciation, a specific intonation pattern or lexical choices) come to be systematically evaluated in particular ways by participants in that setting, as indexing specific social meanings. According to Blommaert (2010), indexical orders are "stratified normative complexes that organize distinctions between, on the one hand, 'good', 'normal', 'appropriate' and 'acceptable' language use and, on the other, 'deviant', 'abnormal' etc. language use" (p. 6; see also Lillis, 2008).

It is essential for the language user to be able to orient to the relevant indexical order and to recognise "what counts as language" in the context in which s/he operates, that is, to recognise what kind of language the addressee is likely to recognise as a functional and credible way of expressing oneself (Blommaert, 2010, 12). When language resources are mediated from one context to another, it is not clear that their functionality and value will remain intact. As Blommaert (2005) argues, the value, meaning and function of linguistic features is dependent on their uptake; they have to be recognised "on the basis of the prevailing orders of indexicality" (p. 72).

The contested nature of the portfolio genre can be analysed from the perspective of a clash between different indexical orders. Norm conflicts are generated in the process of genre use, since this involves the meeting of the norms and values of those representing centre norms (e.g. authors of portfolio writing guidelines and writing instructors) and the norms and values of those representing situated norms (e.g. those who evaluate portfolios on selection committees). Different participants may have widely varying views on what is "normal" or acceptable language use in academic recruitment.

The writers' challenge is to be able to orient to what constitutes legitimate language use from the point of view of those evaluating their writing. In the analysis of normative orders, it is therefore essential to extend beyond the study of centre norms; norms are defined also where they are implemented and where norm adherence is monitored, even if implementation and monitoring are not public processes. 


\section{Data and methodology}

Norms of language use can be studied from a variety of perspectives and in many kinds of data (Woolard, 1998; Irvine, 2002; Hynninen \& Solin, 2017). In the case of an unstable and contested genre such as the teaching portfolio, it is important to analyse not only what linguistic and textual features occur in genre texts, but how writers evaluate the acceptability of particular features. Thus, the present analysis goes beyond the text as an artefact and asks "what is significant and at stake for writers" (Lillis, 2008, p. 367). The analysis focuses, in particular, on the evaluative "metadiscursive" comments interviewees express with respect to genre norms and genre use (see Jaworski et al., 2004; Grésillon \& Perrin, 2014, p. 93-94). These comments relate to specific forms of expression (e.g. self-mention) and broader stylistic choices (e.g. the use of evaluative language), as well as projections of what assumed readers might expect.

The study follows a long tradition of genre research where text analysis is combined with text-based interviews (or "talk around texts"; see Lillis, 2008). The interviews did not only address writers' normative beliefs, but also the linguistic and textual choices they made in their texts. The discussions were retrospective in the sense that the teaching portfolios were not draft versions but final ones and had been submitted by the writers (and in most cases already evaluated) as part of specific application processes.

The data explored in this article was gathered in the context of a research project on genre change in Finnish academia. The project database contains 30 teaching portfolios and interviews with 20 applicants, collected at two large multidisciplinary universities. Interviews were also conducted with university administrative staff and portfolio writing instructors. In addition, the study draws on documents outlining centre norms, such as portfolio guidelines and teaching materials as well as different types of ethnographic evidence (e.g. clippings from university magazines, notes from portfolio writing courses and evaluation statements produced by selection committees). This broader data set is here used to contextualise the discussion of norm conflicts, and more specifically, to describe how the norms of the portfolio genre were mediated to Finnish universities and how writers gained awareness of the genre and genre norms.

Of the 20 writer participants, the analysis focuses on six individuals at one of the universities studied. Three of them represent subjects in the humanities, while the disciplinary orientation 
of the other three is in the sciences. All six had gained a $\mathrm{PhD}$ and some postdoctoral experience at the time of the interviews, and were therefore relatively experienced as research writers. However, they were all novices as portfolio writers. The analysis also draws on interviews with three administrators, who had a role in managing or regulating recruitment processes at the university, and the portfolio guidelines which were available to the applicants.

The interview talk is analysed from a discourse analytic and interactional perspective (see Briggs, 1995; Laihonen, 2008). Instead of treating interview talk as a transparent reflection of "how things are", interviewee accounts are analysed as situated representations, produced within the frame of the research interview genre. Interviewees are assumed to construe beliefs about the genre and perform specific identities in the context of the interaction taking place. The choices of wording in interview talk are treated as significant, as indexing locally meaningful distinctions and evaluations (Lillis, 2008). The teaching portfolio data is commented on from perspectives raised in the interviews, focusing in particular on textual features related to the presentation of the self. ${ }^{1}$

\section{The mediation of genre norms}

Those applying for an academic post in a Finnish setting typically receive guidelines on portfolio writing at the point when a position is declared open. Job announcements include guidelines on how applicants are supposed to document their qualifications for the post, that is, what kinds of genres they should attach to their application (e.g. portfolio, CV, list of publications, motivation letter etc.). More specific guidelines on the various genres can often be found on university websites.

The university studied here regulates the genre through a set of guidelines available online. These guidelines are not a stable code, as they are revised relatively frequently. For the interviewees, however, they were a key source of "centre norms". The document provides guidelines about the expected structure, length and contents of portfolios. According to the guidelines in place at the time of the interviews, portfolios were supposed to contain four structural elements (Basic information, Research and scientific activities, Teaching and supervision, Administration and other activities). The suggested length was 4-7 pages. In contrast to models where the portfolio focuses mainly on teaching activities (hence the term "teaching portfolio"), the guidelines at this university broadened the scope to include other 
academic activities as well. This was reflected in nomenclature; besides using the term "teaching portfolio", the term "academic portfolio" was introduced.

In the guidelines concerning content, we can discern four key areas which the applicant is expected to write about:

- an account of the applicant's professional experience (as a teacher and researcher and in administration),

- an account of the applicant's teaching philosophy and other beliefs and values regarding academic activities,

- evaluations of the applicant's activities as a teacher and researcher (including selfevaluation and an analysis of student and peer evaluations), and

- an account of development plans and "visions" for the future.

While the first type of content is also conventional in the CV, the three other types create a relatively clear distinction between $\mathrm{CVs}$ and portfolios: CVs are typically not expected to include an evaluative gloss on the qualifications listed, nor do they usually describe the applicant's beliefs, values or future plans.

Judging by the data as a whole, the role of institutional portfolio guidelines in the mediation of genre norms is crucial: most of the applicants I interviewed said they had relied on the guidelines when writing their portfolios. A number of interviewees had attended a portfolio course organised by the university's staff development unit, but they also made use of the guidelines. $^{2}$

Most interviewees reported that they had not discussed their portfolios with colleagues or seen others' portfolios. It seems, then, that unlike for many other public genres, genre norms for portfolio writing were not learned through exposure to genre models, with writers evaluating the acceptability of particular genre features on the basis of what they saw other (successful) writers do. The data also indicates that portfolios were usually not taken up for discussion when applicants were interviewed by selection committees, nor were they mentioned in subsequent evaluation statements. Thus, writers' genre knowledge did not tend to develop through a dialogue with other writers and readers.

The teaching portfolio genre appears to belong to the category of academic "occluded genres", together with such genres as application letters, peer review statements and personal 
statements (see Swales, 1996). Even though not all such genres are confidential in nature, they are usually not distributed to a large readership. Thus, writers rarely have models that they can use in their own writing.

Overall, the data suggests that there is little consensus regarding the forms that portfolios should take in order for them to function as useful tools in academic recruitment. While a "genre code" is available for prospective writers, interviewees describe conflicting expectations and valuations regarding genre use. Let me now move on to describe norms conflicts as they are construed in the data.

\section{Norm conflicts}

In the interview data, three main types of norm conflicts are salient. The first conflict relates to whether the genre is understood as being primarily factual or promotional. The second norm conflict concerns whether a reflective orientation is acceptable within the genre and the third whether the requirement to provide facts about the applicant can be managed within a narrative frame.

\section{Factual vs. promotional orientation}

This norm conflict relates to whether the teaching portfolio is perceived primarily as a factual genre (a portfolio is a kind of "written-out CV") or whether it is a marketing genre (where one expected type of content is positive evaluation of the marketed product).

Understood as a genre of self-presentation for the purposes of applying for a job, the teaching portfolio emerges as a clearly promotional genre. The university’s portfolio guidelines list "self-evaluation" as a required content element. The guidelines direct writers to include "selfevaluation of one's teaching and of oneself as a member of the teaching community" and for research "evaluations, feedback, statements, self-evaluation". A "portfolio glossary" on the university's website defines the key contents of portfolios as follows: "employment history, professional philosophy, work products, future plans, obtained feedback and self-evaluation".

We can assume that listing self-evaluation as a required content element will result in portfolios containing some self-promotion; it would be peculiar if a job application document were to contain descriptions of the applicant's weaknesses. However, as shown below, 
positive self-evaluations are often associated with negative indexical meanings in the interviewees' talk.

Interviewees both in the humanities and the sciences describe a tradition where what is valued is the "hard core" of science. They describe normative orders where positive self-evaluations are considered out of place or even in poor taste. In particular, those working in the sciences assume that recruitment decisions are made on the basis of "facts": interviewees refer to traditions of academic recruitment, the conventions of scientific writing and the presumed preferences of readers.

In an interview at a sciences faculty, I asked the interviewee about local norms for expressing positive self-evaluations. She engaged with the issue by describing conventions of research writing in her discipline:

IE: here in the sciences the teaching of writing starts from the assumption that you report facts, you just report facts and you write concisely and using simple sentences, you express yourself clearly and you edit out all the rambling, you're not supposed to use any descriptive words, texts have to be very snappy, very precise, then all of a sudden you have to write a portfolio where you (.) describe yourself and tell about yourself and maybe write some positive things about yourself, some people get really annoyed, I've heard many professors huff and puff with annoyance, look at this writer going on and on $(\mathrm{Sci17})^{3}$

The interviewee describes a relatively normative approach to writing, where what is desirable is being "very snappy very precise". This is construed as contrasting with the descriptive and evaluative text expected in portfolios. The interviewee describes in colourful terms the reaction which a self-promotional text may evoke: "some people get really annoyed", "many professors huff and puff with annoyance". In this account, applicants risk annoying the selection committee if they adhere too closely to institutional genre norms.

An interviewee who worked in biosciences provided further support for this assumption. She expressed a belief that the teaching portfolio, as a genre, requires a personal touch, but also construed it as a generic feature of recruitment in her professional setting that "facts will speak for themselves". 
IR: did you have to think a lot about how clearly you can foreground yourself when you write

IE: not a lot, it's not typical for us, it wouldn't come naturally, but on the other hand this [portfolio] is about my stuff so it was bit more personal than it would have been otherwise, the application processes they tend to be dry and academic [laughs], it's like facts will speak for themselves, that's the tradition, so it's a bit unfamiliar to us (Sci6)

The interviewee presents several generic claims about her own setting; for example, foregrounding the self is not "typical for us" and application processes "tend to be dry and academic".

Her teaching portfolio is in line with this description: it is presented as a list of achievements (jobs held, grants received, courses taught), indexing a CV-like form. In the seven-page document, there are only three paragraphs of text not in list-form, placed under the headings "Research history and future prospects" and "Teaching philosophy". The beginning of the two-paragraph teaching philosophy illustrates the style adopted:

The most important thing in teaching is the teacher's good knowledge of the subject. Expertise gives teacher the ability to filter the most relevant aspects of the subject according to students previous experience and the level of the teaching, being it undergraduate or post graduate teaching. It also helps to choose a pedagogical method that best supports learning of the subject. If evaluation is planned well, it is measuring students' real learning and demonstrates how teaching could be improved. Evaluation together with feedback from students should help to improve the teaching for the next time. (Sci6, original in English)

Throughout this passage, the writer opts to express her beliefs and values in third person, in relatively abstract and generic terms. The writer's self is backgrounded for example through the use of copular clauses ("the most important thing in teaching is...") and non-finite verb forms (e.g. "It also helps to choose a pedagogical method..."). There are no first person forms or other types of self-mention, nor are there any references to the applicant's academic record, evaluative or otherwise (on self-mention in academic texts, see e.g. Hyland, 2001). On the whole, the text reads like an institutional mission statement rather than a personal philosophy. 
In the humanities, of course, traditions of writing are very different. It is difficult to imagine writers being advised to "just report facts" or completely avoiding self-mention. However, writers who worked in humanities disciplines also described norm conflicts around the acceptability and formulation of positive self-evaluations. A writer who had applied for a teaching post in an arts subject assumed that the normative portfolio included evaluations of oneself as a teacher. We discussed, for example, whether it was acceptable in her view to write self-evaluations in the form of unmodalised copular clauses (the suggested example being I am a creative teacher).

IR: if one wants to describe one's successes, what's your view [...] could you think of yourself as writing I'm a creative teacher or something like that

IE: well, the first thing that comes to mind is a personal (.) like I'd think it's boasting, I'm a creative teacher, it would be kind of the same as saying, yeah I'm a brilliant researcher, no, definitely not [said emphatically] you can't say that, you can't write like that anywhere [...] there's something in it, warning lights switch on [...] I could say that I think I've done well as a teacher and then after that I'd refer to student feedback so that I'd have some evidence, it smells of boasting, if I were to read that kind of stuff in somebody's papers I would be irritated, it would seem like marketing (Arts16)

The interviewee's reaction to the suggested wording is strongly negative: the choice of a copular clause and especially the lack of hedging "smells of boasting". "Marketing” appears as something undesirable. Positive self-evaluations are described as needing documentation ("I'd refer to student feedback").

Indeed, this writer's portfolio does not contain such wordings and on the whole, selfevaluation is rare. For example, in the 394-word teaching philosophy description, the only evaluative gloss on the applicant's teaching activity is in a sentence describing student feedback:

The greatest challenge for a teacher is to support students' motivation, commitment to studies and the learner's independence. Two comments from the feedback on [course X] indicate that my teaching has been successful in this respect: ... (Arts16, translated from Finnish) 
While this writer does not avoid self-mention in her portfolio, most descriptions of own activities and beliefs do not include a self-evaluative gloss. Moreover, similarly to the writer in biosciences, the writer appears to prefer wordings where the self is not foregrounded: in the extract above, what is described as successful is "my teaching", not the applicant as a teacher.

Another interviewee, who had applied for a teaching post in a humanities department, also described herself as having reservations about self-promotion. She assumed that colleagues (including those who evaluated her portfolio) were doubtful of the genre because they perceived it as a form of boasting.

IE: the portfolio is almost seen as an object of ridicule, people sneer at it, they say it's just boasting [...] there's a degree of sarcasm towards the whole portfolio format (Arts15)

These examples illustrate self-promotional language becoming associated with negative indexical meanings in a recruitment genre. The interviewees describe positive self-evaluations as being risky as a type of portfolio content: such evaluations are reported to make some readers "huff and puff with annoyance" and to give writers reason to fear the ridicule of their colleagues. The interviewees' portfolio texts signal an orientation towards local, discipline or community-based norms rather than a conscientious application of the "centre norms" expressed in institutional guidelines, for example through the choice of a CV-like format and an avoidance of self-evaluative content which might be interpreted as "marketing" or "boasting".

\section{Factual vs. reflective orientation}

The institutional guidelines available to applicants at the time of data collection define the portfolio genre as a reflective description of one's activities. The guidelines do not define the genre as an administrative one but as a tool for professional development:

The portfolio is primarily a tool for enhancing one's performance. Creating a portfolio requires systematic follow-up and development of one's work, reflection of one's scholarly agenda, self-assessment and assessment by others. 
The "portfolio glossary" on the university's website defined the teaching portfolio as follows: "In the teaching portfolio, the teacher reflects on, presents and documents his/her teaching activities".

In opposition to this normative order, we find an alternative order where reflective writing is associated with uncertainty or even immaturity. One interviewee had attended a writing course organised by the university's staff development unit, where the instructor's feedback had targeted the way she wrote about negative experiences during her teaching career. According to the interviewee, the instructor had intervened in the way she referred to her own uncertainty in a draft version of her portfolio.

IE: the portfolio teacher crossed out quite a few things in my text, hedging and descriptions of difficulties I had experienced, she was really insistent, don't do it like this, you have to foreground the real issues [said emphatically], don't be apologetic, don't make excuses [...] at that point I felt that I didn't want to come across as boasting, I wanted to give an honest account of things I'd felt were difficult or where I felt I had failed (Arts15)

This extract points to an understanding of the genre where reflective writing is not looked upon favourably. Whereas prototypical reflective writing contains hedging and expressions of uncertainty (see e.g. Moon, 2004), in an application portfolio such hedging comes to be interpreted by the instructor as "apologetic" or "making excuses". The writer describes herself as wanting to give "an honest account", not wanting to "come across as boasting".

In her teaching portfolio, the applicant writes:

I think of myself as a person who is energised by new challenges and who learns from mistakes. I have received a great deal of very positive student feedback ... and have tried to learn from negative feedback. (Arts15, translated from Finnish) The writer explained in the interview that this passage had originally been longer, describing her experiences of a lecture course which she had been unhappy with and which was not wellreceived by students. After receiving feedback on her draft portfolio, she deleted this description. All that was left was the mention of her commitment to "learn from negative feedback". This example serves to illustrate a conflict between institutional norms (portfolios 
should include a reflective element) and expectations regarding how to present oneself in the context of recruitment.

A second writer describes a norm conflict where the opposing orders were a genre model learned during pedagogical training and the expectations of the local selection committee. This writer had gained an understanding of the genre while completing teacher training. This portfolio model was evaluated as "immature" in the context where the writer applied for a job (a unit in the Faculty of Arts).

IE: I was told that my portfolio was immature [...] during pedagogical training we were told that we should write about our own thoughts and feelings and how we experience our work but in this case I think what the selection committee probably expected or what they would have thought to be mature would have been something more academic and impersonal (Arts2)

The norm conflict here is created between norms learned during teacher training and the expectations of the selection committee - in one context the description of "own thoughts and feelings" is a required feature of the genre, while in the other, readers are reported to expect something "impersonal". The example illustrates the local and situated nature of norms as well as their instability and polycentricity: a feature valued in one context - the personal and reflective orientation - is evaluated in a completely different manner in another context - as immaturity.

An extract from the first page of this writer's portfolio gives a flavour of the style she adopted:

When I was asked, at the age of 24, whether I would like to pursue doctoral studies [...] I thought that even if it turns out I'm not cut out to be a researcher, I could still go back and learn another profession. So I agreed to give it a try and see whether I'd like writing a licentiate thesis. I still had some money left from my student grant and did not need to apply for a full-time job immediately. (Arts2, translated from Finnish)

The portfolio begins with a personal narrative, going back to the moment when the writer decided to start doctoral studies. The writer opts for a first-person account, with verbs describing thought processes, emphasising feelings of uncertainty and doubt regarding an academic career ("I could still go back", "I agreed to give it a try"). These linguistic choices 
are clearly in line with the genre model she describes as having influenced her writing, but were interpreted as a misunderstanding of the genre by the target readers.

These examples illustrate situations where the writer orients to what she assumes are relevant norms in the teaching portfolio genre and receives negative feedback as a result. In the first case, the writer revised her portfolio after receiving feedback from a writing instructor, while in the second, the feedback came from the selection committee. Both serve as an example of how an "honest account" or a description of "thoughts and feelings" come to be interpreted as inappropriate in the context of academic job-seeking.

An interview with an administrator also points to a conflict between factual and reflective orientations. The interviewee, who processed teaching portfolios as part of her work, offered a new perspective on reflective writing. From her position, many writers had problems with "writing in third person".

IE: when people start describing their teaching philosophy or something like that they sometimes include really personal things, some people can write it like it's expository text, this is how it is, they sort of write in third person about themselves but not everyone can do it (Adm6)

What is established as desirable from the point of view of administration is "expository text", while "personal things" are evaluated as problematic.

In this interviewee's account, a central concern is the writer's right to privacy and the administrator's need to respect privacy laws by avoiding the distribution of private information about applicants. While the application portfolio is officially a public document, the administrator implies that many writers are perhaps not aware of this: "you almost feel a bit embarrassed, some writers go into so much detail". The interviewee describes a process by means of which application documents are edited by administrative staff and information perceived as sensitive is hidden.

IE: if there's any sensitive information, we've had to blacken some of the text before making it public, we've had to put black tape on some of what they've written so we won't be sued for breaking privacy laws [...] whoever goes through the application documents has to be really careful and check that everything in the papers can be sent forward, there can be astonishingly private stuff (Adm6) 
From the position of an administrator, the way that some writers interpret reflective writing in the context of the portfolio genre is problematic, specifically from the point of view of administrative processes and legal concerns. Unlike members of selection committees, who look for information about the merits of the different applicants, administrative staff check the texts in order to make sure that the applicant's privacy is not jeopardised. Thus, reflective writing also gains negative indexical meanings from the administrator's perspective, not because it is evaluated as apologetic or immature, but because it affects the way in which portfolios can be used during the recruitment process.

\section{Factual vs. narrative orientation}

The third norm conflict is construed between a factual orientation and a narrative orientation. The data show that both writing instructors and teaching materials encourage writers to structure their portfolio as a narrative of progress. For example, in the online "portfolio glossary", the genre is defined as a description of "the development of the individual's abilities and competence". Writers are encouraged to describe their work history from the point of view of how they have developed in their profession, rather than simply giving a list of qualifications and activities.

However, on the basis of the interview data, the norm of framing one's professional life as a narrative of progress does not appear to be functional in all contexts. The narrative form is challenged in the account of an interviewee who worked in a sciences faculty. She described the narrative norm as something she was introduced to during a portfolio writing course.

IE: the instructor emphasised that the portfolio has to be a story and it has to rise to a kind of meta-level over and above being just a list of what you've done [...] the instructor wasn't very happy with my draft portfolio, it was apparently too much of a list or description of what I've done, it wasn't what it was supposed to be (Sci10)

Here we have an opposition between "lists" and a "story" which moves to a "kind of metalevel". However, the interviewee expresses reservations regarding the story form:

IE: I wondered what the selection committee would think, they are not used to this sort of thing either, how will they read it [...] I thought if I were the reader I would be more interested in the facts, what has the person done, what kinds of evidence are there about what they can do (Sci10) 
The interviewee suggests that selection committees may in fact be more interested in what she calls "evidence" than in narratives. Moreover, she indicates that the instructor's understanding of the genre may not be functional in the context being targeted. That is, the narrative norm may not be in alignment with the intended readers' view about an acceptable way of describing professional qualifications.

The interviewee's portfolio illustrates an attempt to balance the institutional push towards a narrative form and the provision of details about her record. The text is fully in line with the institutional guidelines: seven pages long, including all four required content elements, with a $\mathrm{CV}$ and list of publications appended. The three-page section entitled "Research and other scientific activities" is particularly interesting from the perspective of balancing between a factual and a narrative approach. It is chronologically organised, describing the applicant's career in terms of discrete stages (graduate student, doctoral student, post-doctoral researcher, senior scientist). Each stage is delineated in terms of which topics the applicant studied, what projects she participated in and what publications ensued. However, the descriptions also include occasional evaluative commentary regarding how the applicant's knowledge and skills developed during the period, pointing to an attempt to move away from list-like presentation and towards a narrative of development. The following is an example of such an evaluative frame:

In my first post-graduate project [...] I was looking at $[\mathrm{x}]$ using the $[\mathrm{x}]$ approach. [...] The project taught me a lot about sampling methods and assessing the adequacy and representativeness of sampling, in addition to leading to some unexpected results [...] It opened my eyes to see the fascination of the complex interactions in [x] functioning, and the importance of a holistic view in understanding $[\mathrm{x}]$ functioning. Not to mention the need of constantly challenging one's own thinking about how things work and why. (Sci10)

The applicant explains the topics she studied and the methods she used, but frames it in terms of what she learned, both in terms of learning about technique, but also broader issues such as being able to identify "complex interactions" in the data and learning to challenge one's thinking. Compared to a CV-like presentation, this frame allows the description of one's record as a dynamic, forward-moving trajectory of professional development. 
University administrators described the narrative form as potentially problematic in terms of how it was interpreted by some applicants. One interviewee talked about "stream of consciousness portfolios" and "outpourings" (Adm7), while another referred to "rambling" portfolio texts:

IE: in recruitment processes there have been some really shocking packages of documents which have nothing to do with the original purpose of portfolios [...] so those who want to snigger at this kind of qualitative evaluation and trying to evaluate people's abilities, they've had a field day when they've seen these piles of documents measuring three feet, feedback forms from students and ramblings that somebody wanted to share about their own development (Adm3)

Here the narrative form gains negative indexical meanings by being associated with "ramblings", the idea that some writers submit overly long and meandering texts for review. The interviewee refers to "shocking packages of documents" as affecting the reputation of the genre (those who are already critical will "have a field day"). This account describes a situation where the genre is mocked because writers include too much detail in their portfolios, not (just) because the portfolios are interpreted as boastful.

\section{Conclusion}

This article has examined the take-up of a new genre from the point of view of norm conflicts. In the data, conflicts are construed between the ideals which norm authorities put forward and what kinds of portfolio texts readers are assumed to prefer. Portfolio guidelines and writing instructors present applicants with a genre model in which it is important to describe one's merits, but also evaluate them and present one's work history in the form of a narrative. The guidelines further encourage applicants to reflect on their activities in their portfolio. In contrast, applicants describe readers who are assumed to value something different: "evidence", "lists", being "impersonal" and "precise". Members of selection committees are reported to be irritated by "boasting" and "rambling". As one interviewee put it, "facts will speak for themselves". Many interviewees either predict or describe a situation where positive self-evaluations, reflective writing or narratives come to have negative indexical meanings in the context of academic job-seeking. Readers are described as "huffing and puffing with annoyance", "sneering at portfolios" or finding the applicant's text to be immature. 
The writers describe having to orient to other normative orders besides the one set forth in the institutional guidelines. The instability of the genre is not due to a lack of consensus among norm authorities or lack of a code; it relates rather to the diversity of normative expectations among different groups of genre users. The individual applicant's challenge is to be able to predict what norms are relevant in any given situation and for a given readership.

An orientation to multiple sources of norms is evident also in the teaching portfolios the interviewees had produced for the purposes of job-seeking. The data shows many writers drawing on the conventions of the CV in order to ensure the inclusion of enough "facts". The writers avoid language which could potentially be interpreted as "boasting", some by completely avoiding self-mention, others by avoiding evaluative adjectives as descriptors of own characteristics (e.g. "I'm a creative teacher."). However, the writers also orient to centre norms for example by editing out expressions of uncertainty or by trying to describe their career in terms of a narrative of professional development.

Besides institutional guidelines, interviewees talked about teaching portfolios in relation to conventions of self-presentation in academia and the assumed preferences of their (senior) colleagues. They referred to how things are usually done in their corridor, in their discipline, on the sciences campus, what is "typical for us". It is evident that the take-up of a new genre is affected by the variety of generic resources which genre users already draw on and recognise as legitimate in their professional setting. Such resources are specific to disciplinary communities and organisational cultures.

This points to the importance of a focus on indexical meaning in the analysis of genre change. There are several examples in the data of how a linguistic feature or type of writing valued in one context gains completely different meanings in other contexts. A dramatic example of such shifts is the valuation of reflective writing as desirable in the context of pedagogical training, as a sign of immaturity in the context of a selection committee and as a privacy issue for university administration. Similarly, (positive) self-evaluation is described as evoking irritation and ridicule in some contexts, despite being a normative feature of self-presentation in most recruitment genres.

The data illustrates contextually specific evaluations of what is acceptable in the teaching portfolio genre, relating to even very small details of language use. From the perspective of genre theory and methodologies of genre analysis, this points to the necessity of 
conceptualising genre norms as situated and negotiable, even in cases where genres are the focus of top-down regulation. It also calls for methodologies which are sensitive to contextual variation and interested in the diversity of normative expectations and evaluations that come to play when genre users negotiate questions of acceptability.

The study also demonstrates the discourse aspect of new practices of management and emphasises the need for an analysis of organisational change in terms of language use and genres. Genres are not neutral technologies, but are imbued with social and cultural values and meanings. The teaching portfolio case illustrates a process in which the value of linguistic resources does not remain the same when the resources are transferred from one context to another (cf. Blommaert, 2005). From the perspective of genre, this means that whenever genre resources are adopted or borrowed, there is a risk that these resources will not come to be evaluated by new users as predicted. There are no guarantees that they will be ratified as acceptable linguistic behaviour or that the indexical meanings of genre features remain the same in the new context.

\section{References}

Bakhtin, M. (1986 [1953]). The problem of speech genres. In C. Emerson, \& M. Holquist (Eds.), Speech genres and other late essays (pp. 60-102). Austin: University of Texas Press.

Beaufort, A. (2000). Learning the trade. A social apprenticeship model for gaining writing expertise. Written Communication, 17, 185-223. doi: 10.1177/0741088300017002002

Blommaert, J. (2005). Discourse. Cambridge: Cambridge University Press.

Blommaert, J. (2010). The sociolinguistics of globalisation. Cambridge: Cambridge University Press.

Briggs, C. (1995). Interview. In J. Verschueren, J. Blommaert, \& J-O Östman (Eds.), Handbook of pragmatics manual (pp. 601-606). Amsterdam: John Benjamins.

CAUT (1986). The teaching dossier. Ottawa: Canadian Association of University Teachers.

Connell, I., \& Galasiński, D. (1998). Academic mission statements: an exercise in negotiation. Discourse \& Society, 9, 457-479. 
Coppola, B. (2002). Writing a Statement of Philosophy. Journal of College Science Teaching, $31,448-453$.

Devitt, A. (2004). Writing genres. Carbondale, IL: Southern Illinois University Press.

Grésillon, A., \& Perrin, D. (2014). Methodology: from speaking about writing to tracking text production. In E-M. Jacobs, \& D. Perrin (Eds.), Handbook of Writing and Text Production (pp. 79-112). Berlin: De Gryuter.

Hyland, K. (2001). Humble servants of the discipline? Self-mention in research articles. English for specific purposes, 20, 207-226. doi: 10.1016/S0889-4906(00)00012-0

Hynninen, N., \& Solin, A. (2017). Language norms in ELF. In J. Jenkins, W. Baker \& M. Dewey (Eds.), Routledge Handbook of English as a Lingua Franca (pp. 267-278). London: Routledge.

Hyon, S. (2011). Evaluation in tenure and promotion letters: constructing faculty as communicators, starts, and workers. Applied linguistics, 32, 389-407. doi: $\underline{10.1093 / a p p l i n / a m r 003}$

Irvine, J. (2002). "Style" as distinctiveness. The culture and ideology of linguistic differentiation. In P. Eckert, \& J. R. Rickford (Eds.), Style and sociolinguistic variation (pp. 21-43). Cambridge: Cambridge University Press.

Jaworski, A., Coupland, N., \& Galasiński, D. (Eds.) (2004). Metalanguage. Social and ideological perspectives. Berlin: Mouton de Gruyter.

Knapper, C., \& Wright, A. (2001). Using portfolios to document good teaching: premises, purposes and practices. New Directions for Teaching and Learning, 88, 19-29. doi: $\underline{10.1002 / \mathrm{tl} .34}$

Laihonen, P. (2008). Language ideologies in interviews: a conversation analysis approach. Journal of Sociolinguistics, 12, 668-693. doi: 10.1111/j.1467-9841.2008.00387.x

Leggett, M., \& Bunker, A. (2006). Teaching portfolios and university culture. Journal of Further and Higher Education, 30, 269-282. doi: 10.1080/03098770600802297 
Lillis, T. 2008. Ethnography as method, methodology and "deep theorising”. Written Communication, 25, 353-388. doi: 10.1177/0741088308319229

Miller, C. (1984). Genre as social action. Quarterly Journal of Speech, 70, 151-167. doi: $\underline{10.1080 / 00335638409383686}$

Moon, J. (2004). Handbook of reflective and experiential learning. London: Routledge.

Piippo, I. (2012). Viewing norms dialogically: An action-oriented approach to sociolinguistic metatheory. Helsinki: Department of Modern Languages, University of Helsinki.

Pires Pereira, I.S. (2014). Writing and the situated construction of teachers' cognition: portfolios as complex performative spaces. Language and Education, 28, 521-538. doi: $\underline{10.1080 / 09500782.2014 .908904}$

Reiff, M. J., \& Bawarshi, A. (2011). Tracing discursive resources: how students use prior genre knowledge to negotiate new writing contexts in first-year composition. Written Communication, 28, 312-337. doi: 10.1177/0741088311410183

Seldin, P. (1993). Successful use of teaching portfolios. Bolton, MA: Anker Publishing.

Silverstein, M. (2003). Indexical order and the dialectics of sociolinguistic life. Language and Communication, 23, 193-229. doi: 10.1016/S0271-5309(03)00013-2

Solin, A. (2009). Genre. In J. Verschueren, \& J-O Östman (Eds.), Handbook of pragmatics. Amsterdam: John Benjamins.

Swales, J. (1990). Genre analysis: English in academic and research settings. Cambridge: Cambridge University Press.

Swales, J. (2004). Research genres. Exploration and applications. Cambridge: Cambridge University Press.

Swales, J. (1996). Occluded genres in the academy: the case of the submission letter. In E. Ventola, \& A. Mauranen (Eds.), Academic writing: intercultural and textual issues (pp. 45-58). Amsterdam: John Benjamins. 
Woolard, K. (1998). Introduction. Language ideology as a field of inquiry. In B. Schieffelin, K. Woolard, \& P. V. Kroskrity (Eds.), Language ideologies. Practice and theory (pp. 347). Oxford: Oxford University Press.

Wouters, P., Clement, M., Frenay, M., Buelens, H., \& Gilis, A. (2014). Avoiding compliance and resistance through collaboration? A Belgian teaching portfolio case. International Journal for Academic Development, 19, 26-36. doi: 10.1080/1360144X.2013.848359

\footnotetext{
${ }^{1}$ All interviews were semi-structured and lasted 60-80 minutes. In line with the local ethical guidelines, each participant was asked for written consent to use the interview and the teaching portfolio for research purposes. In order to protect the participants' anonymity, I do not provide detailed information about their disciplinary or organisational affiliation.

${ }^{2}$ Portfolio courses organised by the university typically involved each participant preparing a draft portfolio, commenting on others' portfolios in small groups and receiving feedback on their portfolio from the course instructor.

${ }^{3}$ The interviews were conducted in Finnish. Four of the teaching portfolios analysed were in Finnish, two in English. The Finnish data extracts have been translated into English by the author. In the extracts from interviews, the symbol (.) indicates a short pause. Three dots within square brackets indicate that part of the interviewee's speech has been left out. Square brackets are also used to mark comments and explanations added by the transcriber and the researcher.
} 